\title{
Economia afetiva e capital emocional em cena: o star system hollywoodiano revisitado em comerciais de perfumes na TV
}

Denise Azevedo Duarte Guimarães

Resumo: $\mathrm{O}$ artigo examina recentes comerciais televisivos de perfumes, dirigidos por três renomados cineastas, com ênfase nos modos de representação das imagens femininas e nos recursos estilísticos bastante similares. Abordam-se a evocação da ilusão cênica típica do cinema e as glamorosas imagens das "divas", já cultivadas pelo star system, em meados do século XX. O texto também aponta as estratégias persuasivas comuns aos três produtos audiovisuais; numa retórica que gira em torno de objetos do desejo e do status, com apelos ao luxo, aos prazeres e às sensações exacerbadas, construídos como polos de identificação para mulheres contemporâneas.

Palavras-chave: cinema; televisão; publicidade

Abstract: Affective economy and emotional capital on the screen: Hollywood's star system revisited in $T V$ ads for perfume - The article examines recent TV perfume ads directed by three famous filmmakers, focusing on the ways in which women's images are represented and on the very similar stylistic devices. It addresses the evocation of scenic cinematic illusion and the glamorous images of "stars" cultivated by the star system as early as the mid- $20^{\text {th }}$ century. The text also identifies the persuasive strategies common to the three audiovisual products, which employ a rhetoric centered upon objects of desire and status, with the allure of luxury, pleasures and enhanced sensations offered as points of identification for contemporary women.

Keywords: cinema; television; publicity.

\section{Considerações iniciais}

Em discussões ambientadas no contexto mais recente, avulta o tema das profícuas interfaces intermidiáticas, algo que não é inédito, mas que tende a explorar novos formatos 
na cultura da convergência. Nessa tentativa de extensão de mercados potenciais, cada produto aponta para a popularidade de outros com os quais dialoga e vice-versa, de modo que as interações recíprocas funcionam de maneira sinérgica. Henry Jenkins, em 2009, esclarece os termos:

O pessoal da indústria usa o termo "extensão" para se referir à tentativa de expandir mercados potenciais por meio do movimento de conteúdos por diferentes sistemas de distribuição; "sinergia", para se referir às oportunidades econômicas representadas pela capacidade de possuir e controlar todas essas manifestações; e "franquia", para se referir ao empenho coordenado em imprimir uma marca e um mercado a conteúdos ficcionais, sob essas condições. Extensão, sinergia e franquia estão forçando a indústria midiática a aceitar a convergência (JENKINS, 2009, p. 47).

Acreditamos que, nesse contexto, as interlocuções ficcionais entre o mercado e as grifes viabilizam a integração da qualidade técnica e dos efeitos estéticos, próprios do cinema, à publicidade televisiva, em seus rigorosos processos de construção e mecanismos persuasivos. O recorte deste artigo centra-se em comerciais de perfumes femininos de grife dirigidos por renomados cineastas, sob o viés de como as lógicas interacionais são, especificamente, neles constituídas.

O fenômeno é ostensivo atualmente, sobremaneira nos canais por assinatura; contudo, não é algo novo. Federico Fellini dirigiu filmes do Campari por volta de 1960, David Lynch produziu peças publicitárias televisuais para a Calvin Klein em 1988 e continua produzindo filmes do gênero até hoje. Cineastas como Ridley Scott, Baz Luhrmann, Sofia Coppola, Jean-Pierre Jeunet, Guillermo Del Toro, Olivier Dahan, Frank Miller, Wong KarWai, entre outros, estão sendo continuamente requisitados pelo mundo da moda e da perfumaria para suas campanhas. ${ }^{1}$ Nelas, além dos orçamentos milionários, não faltam celebridades, top models ou atrizes e atores atraentes.

Sob o viés socioantropológico, Néstor García Canclini (2008) esboça a construção de uma teoria sociocultural do consumo em tempos de globalização, em três vertentes: a primeira, com o foco no ciclo de produção e reprodução social, ou seja, uma racionalidade econômica; a segunda, voltada para os movimentos dos consumidores e suas demandas, em termos de uma racionalidade sociopolítica interativa; e, a terceira, voltada para aspectos simbólicos e estéticos que estabelecem a necessária tensão e a diferenciação entre grupos, através de uma racionalidade consumidora.

Nós, seres humanos, intercambiamos objetos para satisfazer necessidades que fixamos culturalmente, para integrarmo-nos com outros e para distinguirmos de longe, para realizarmos desejos e para pensar nossa situação no mundo, para controlar o fluxo errático dos desejos e dar-lhe constância ou segurança em instituições e rituais (CANCLINI, 2008, p. 71).

1 Os filmes O Diabo veste Prada (2006) e Sex and the city (2008) demonstram a referida convergência, no caso, entre cinema, moda (grifes) e publicidade. 
Nossa proposta é observar o universo publicitário das grifes de perfumes, de modo a tecer algumas reflexões teóricas e críticas sobre seus contornos simbólicos e estéticos. Almejamos atestar como, nos comerciais televisivos das novas fragrâncias, além do glamour das celebridades, cada diretor traz seu estilo e a contribuição milionária da indústria cinematográfica. Abordaremos três comerciais do gênero, veiculados recentemente na TV paga, o que já lhes imprime um diferencial no que concerne ao segmento de públicoalvo. São produtos que passam a incorporar novas temporalidades e espaços expressivos. Neles, investigaremos os modos de representação das imagens da mulher, sob o viés de recursos estilísticos bastante similares e das estratégias persuasivas comuns a eles. Todos são, porém, bastante diferentes, porque cada diretor imprimiu seu estilo cinematográfico ao filme comercial por ele dirigido. As peças publicitárias a serem comentadas são, respectivamente, dirigidas por Jean-Pierre Jeunet (Chanel no 5), Sofia Coppola (Miss Dior Chérie) e Wong Kar-Wai (Dior Midnight Poison).

\section{Sutilezas e obviedades dos signos icônicos nos comerciais de perfumes}

O ato de observar atentamente um conjunto expressivo de filmes publicitários recentes, na escolha do corpus para este artigo, permitiu-nos perceber a configuração audiovisual de uma espécie de estilo para as mensagens que divulgam perfumes, cujas características aproximam-se perigosamente da estereotipia. Nelas, evocam-se, a todo instante, a ilusão cênica típica do cinema e as imagens glamorosas, anteriormente cultivadas pelo star system; ambientadas em cenários cosmopolitas ou espaços com belezas naturais exóticas, que passaram a uma espécie de locus utopicus das referidas grifes voltadas a um público-alvo segmentado. A retórica da persuasão gira em torno de apelos ao luxo, aos prazeres e às sensações exacerbadas por objetos do desejo e do status, construídos como polos de identificação para a mulher contemporânea.

Tudo isso nos leva a refletir sobre como, fora do contexto filosófico e intelectual, a mulher ainda segue modelos clássicos de beleza e as atrizes representam sua imagem ideal. Segundo Nancy Etcoff, é como se existisse dentro de cada ser humano um modelo que é encontrado assim que é visto.

O ser humano, mulher ou homem, por ser imperfeito pode aperfeiçoar-se infinitamente. Por isso desejamos ser, além de obras da natureza, obras de arte; mais do que imitar, desejamos nos aperfeiçoar: ter uma representação externa que harmonize com nossos sonhos, visões e aspirações morais (ETCOFF, 1999, p. 24).

Embora revestidas de aparente atualidade e modernidade, as mulheres representadas nos comerciais abordados, paradoxalmente, são emblemas do desejo de agradar, ligado historicamente ao universo feminino, sob as formas da sedução ou do encantamento. Ainda hoje, permanecem muitos dos mecanismos operados pela linguagem cinematográfica 
que constroem, discursiva e esteticamente, a imagem da "diva" com base no modelo de star system, definido por Edgar Morin como "máquina de fabricar, manter e promover as estrelas sobre as quais se fixaram e se divinizaram as virtualidades mágicas da imagem da tela" (MORIN, 1989, p. 77).

Vemos, então, que a imagem corpórea idealizada atinge o estatuto de simulacro, num conjunto de representações que persistem no imaginário coletivo atual, no que concerne à mulher, muito embora devidamente atualizadas; o que nos permite afirmar que sua elaboração, nos comerciais analisados, apropria-se dos jogos de linguagem e das práticas de teor artístico advindas da sétima arte.

\section{Um olhar cinematográfico sobre as estrelas e celebridades}

Segundo Rogério Covaleski, as artes em geral, e o cinema em especial, juntamente com a televisão, são referências importantes para os criadores publicitários. "Além do apelo emocional e estético que a obra cinematográfica propicia e do fascínio exercido sobre a maioria das pessoas, é uma fonte quase inesgotável de ideias, formatos e linguagens [...]" (COVALESKI, 2009, p. 65). Nesse sentido, a observação de casos levou-nos a problematizar o tratamento tecnoestético conferido à imagem feminina nos comerciais do gênero e, para tanto, selecionamos os três filmes publicitários a serem comentados, com objetivos específicos em mente: de início, verificar um caso de narrativa romântica, com o previsível happy end. A seguir, apontar as tendências mais exploradas: aquelas que envolvem belas mulheres, em situações sensuais e extravagantes. Escolhemos cineastas de diferentes nacionalidades para tentar sugerir o leque de possibilidades que o referido gênero de comerciais vem ampliando, de acordo com a lógica cultural da convergência.

O diretor francês Jeunet segue um roteiro tradicional, dentro do ritmo lento do cinema europeu, mais associado à contemplação estética. Sem abandonar seu primoroso estilo do filme $O$ fabuloso destino de Amélie Poulain (2001), apesar das exigências de velocidade imposta pelos comercias da TV, o cineasta consegue apresentar uma narrativa ficcional completa, com princípio, meio e fim, em apenas $2{ }^{\prime} 25^{\prime \prime}$.

A norte-americana Coppola tenta recriar a atmosfera romântica e as opções cromáticas de seu filme Maria Antonieta (2006), porém adere claramente ao star system, ao escolher como protagonista Natalie Portman, a ganhadora do Oscar daquele ano (em Cisne Negro, 2011), além de efetuar referências intertextuais ao filme do outro cineasta.

Por sua vez, o chinês Wong parece abandonar completamente seu anterior estilo intimista e lírico ${ }^{2}$ para elaborar um filme também híbrido, em que reinam a estilização, a paródia, a apropriação e uma intertextualidade exacerbada. Percebe-se, no referido comercial, um mergulho intenso no estilo hollywoodiano que o cineasta assumiu em seus últimos filmes.

2 Entre os mais conhecidos: Amor à flor da pele (2000), Anjos caídos (1995) e Amores expressos (1994). 
Cumpre lembrar que, num procedimento já padronizado nos comerciais de perfumes femininos (ou masculinos), o frasco colorido com o nome do produto aparece apenas no final, com o som de uma in off que diz o nome da nova fragrância em outro idioma, sem legendas. Acreditamos que se trata de um reforço a um tipo de apelo destinado a uma classe privilegiada que, em tese, dominaria línguas estrangeiras e se identificaria com o modo de veiculação da propaganda.

\section{a) Jean Pierre Jeunet \& Chanel $n^{\circ} 5$}

No comercial da mais conhecida fragrância da maison de Coco Chanel, dirigido por Jean Pierre Jeunet, Audrey Tatou, em papel muito semelhante ao de Amélie Poulain, contracena com Travis Davenport. O clima do filme é mantido nesta viagem noturna de trem, hábito europeu que sempre rendeu boas histórias para o cinema. Assim como a protagonista do comercial, sempre com sua máquina fotográfica, Amélie também viaja e fotografa tudo o que acha interessante.

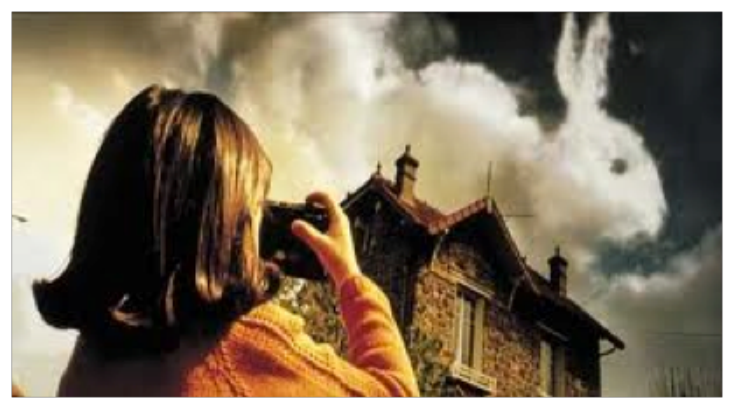

Fig. 1. Frame do comercial de Jeunet ${ }^{3}$.

A peça audiovisual dirigida por Jeunet também explora algumas tendências da cultura de massa, referidas por Edgar Morin (2005), como o lazer (escapismo), a valorização da juventude, o happy end (segurança), a felicidade e o amor. A inclusão do rapaz na narrativa liga-se a um estilo também estereotipado nos comerciais de perfumes: um par amoroso chega a um final feliz. O diferencial é dado pela concepção esmerada do diretor francês, principalmente no timing das cenas, no uso da câmera e na exploração de nuances cromáticas inusitadas. São reverberações do cinema du look, como a sobrevivência da ostentação estética nos filmes franceses. As fantasias daquele estilo cinematográfico têm como base a necessidade do distanciamento da representação do real, num momento delicado da realidade pós-industrial francesa, como explica Isabelle Vanderschelden, em seu livro sobre o filme $O$ fabuloso destino de Amélie Poulain:

3 Todos os frames dos comerciais de perfumes foram capturados no Youtube (www.youtube.com/watch?) pela autora em diferentes datas. 
Besson and Beineix in particular proposed a high-tech popular cinema influenced by Hollywood, and appealing to young audiences, which became known as the cinema du look. [...] Jeunet and Caro have been associated with cinema du look on several accounts. Both Delicatessen and La Cité des Enfants perdus were influenced stylistically by commercials and bande dessinée aesthetics, and the "look" style (VANDERSCHELDEN, 2007, p.16). ${ }^{4}$

No que concerne ao estilo, no filme de 2001, o diretor não foge muito a suas obras anteriores, com cores saturadas, movimentos de câmera (às vezes até zooms abruptos) e planos fechados no rosto dos atores. Isso também ocorre no comercial do Chanel $n^{\circ} 5$. Percebe-se, nos dois produtos, a saturação do vermelho-escuro, do ocre, do sépia e do verde: uma escala cromática característica do estilo do cineasta.
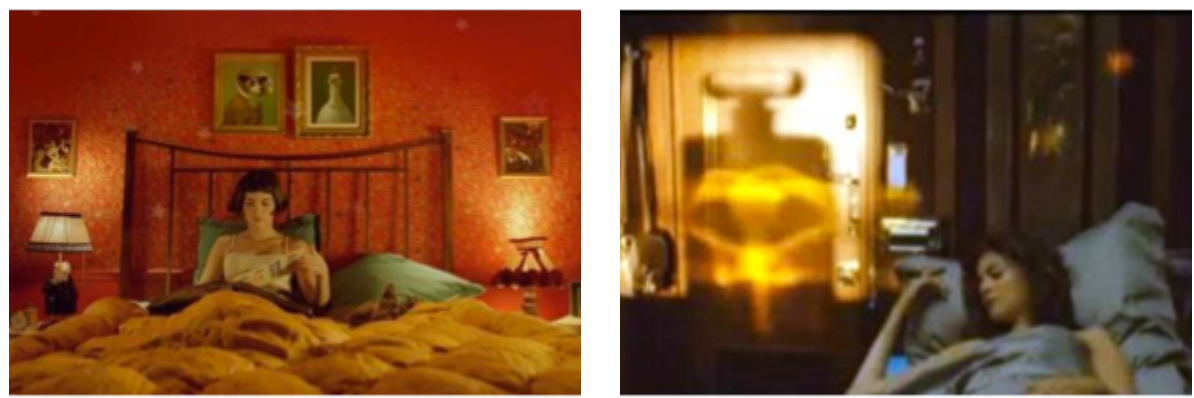

Fig. 2. Frame do filme $O$ fabuloso destino de Amélie Poulain ${ }^{5}$ e frame do comercial de Jeunet.

Em O fabuloso destino de Amélie Poulain, o diretor utiliza seguidamente a câmera em plongé e a movimenta para baixo, com o efeito de fusão. A última sequência do comercial utiliza também a câmera alta, justamente na estação ferroviária, como acontece no filme. Nessa cena, em que aparece sozinha em uma grande estação de metrô, a protagonista torna-se diminuta diante da impressão da altura do ambiente, conseguida pela posição da câmera. As grandes portas e janelas dispostas em sequência ampliam as proporções, juntamente com uma iluminação difusa e amarelada, muito utilizada no decorrer do filme. São ambientes similares e até mesmo as linhas de convergência das paredes sugerem a sensação de vertigem: o mise-en-abyme.

4 Tradução: Besson e particularmente Beineix propuseram um cinema popular de alta tecnologia influenciado por Hollywood, e atraente para espectadores jovens, que ficou conhecido como cinema du look. [...] Jeunet e Caro têm sido associados com o cinema du look em vários momentos. Ambos Delicatessen e La Cité des Enfants Perdus foram estilisticamente influenciados pelos comerciais e pela estética de tiras em quadrinhos, e o estilo "du look".

5 Todos os frames dos filmes foram capturados dos respectivos DVDs pela autora do artigo. 


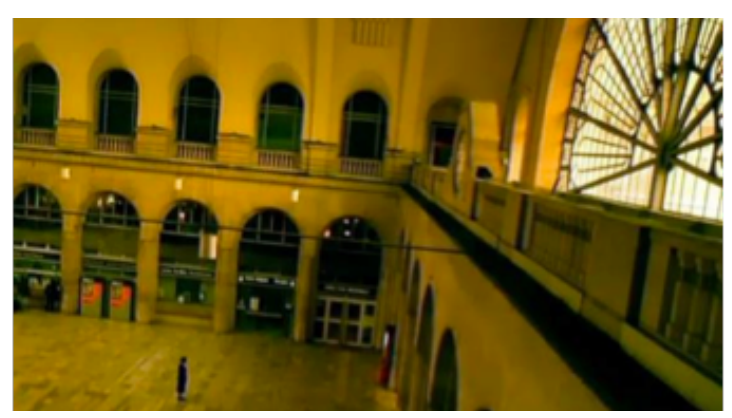

Fig. 3. Frame do filme $O$ fabuloso destino de Amélie Poulain.

No fotograma do longa-metragem de Jeunet, bem como no comercial abordado, destaca-se uma construção em abismo, onde o olhar segue o ponto de fuga e cria a sensação de que as laterais se repetem vertiginosamente até o encontro das linhas de perspectiva. Por outro lado, colocar algo em "abyme" significa também representá-lo no centro de um círculo, que poderia ser um escudo protetor, no caso desenhado no chão com a logomarca da Chanel, sobre a qual os dois se abraçam; a imagem só perceptível quando a câmera vai baixando sobre o casal.

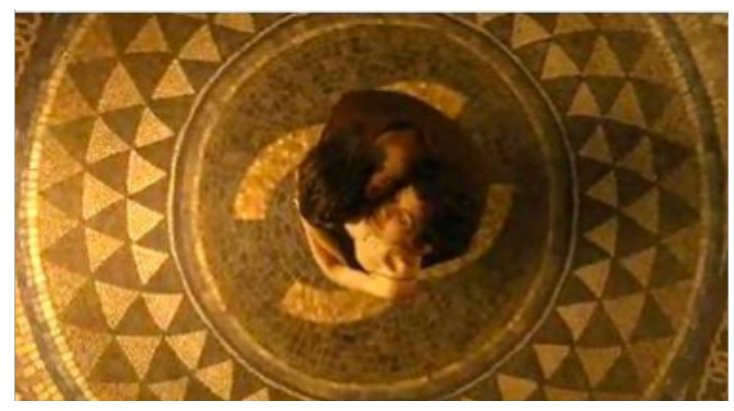

Fig.4. Frame do comercial de Jeunet.

Na peça produzida por Jeunet, percebemos uma dimensão simbiótica que poderia ser associada ao binômio conceitual projeção-identificação, desenvolvido por Edgar Morin: “[...] esse universo imaginário adquire vida para o leitor se este é, por sua vez, possuído e médium, isto é, se ele se projeta e se identifica com os personagens em situação, se ele vive neles e se eles vivem nele"(MORIN, 2005, p. 78). 


\section{b) Sofia Coppola \& Miss Dior Chérie}

Este é o segundo comercial da diretora para a mesma fragrância da Dior, porém revela-se bem diferente do anterior, que remete estilisticamente a seu filme Maria Antonieta, de 2006. Agora, tem-se uma exploração do auge da atriz Natalie Portman, ganhadora do Oscar em Cisne Negro (2011), premiado filme de Darren Aronofsky.
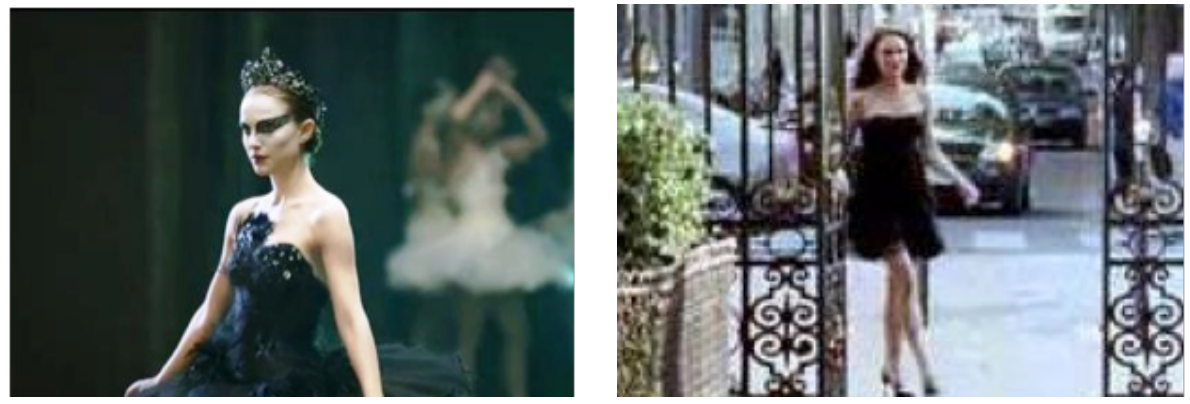

Fig.5. Frame do filme Cisne Negro e frame do comercial de Sofia Coppola

De outra perspectiva, bem ao estilo do filme Maria Antonieta, trata-se de uma narrativa centrada na mulher, numa ambígua atmosfera de lembrança ou sonho, em que ela se vê como dominadora, apesar de ser apresentada com rosa e tons suaves. Dentre as referências intertextuais, destaca-se, pela estranheza dos óculos escuros, a cena do banho, muito semelhante à que aparece no referido filme da cineasta.
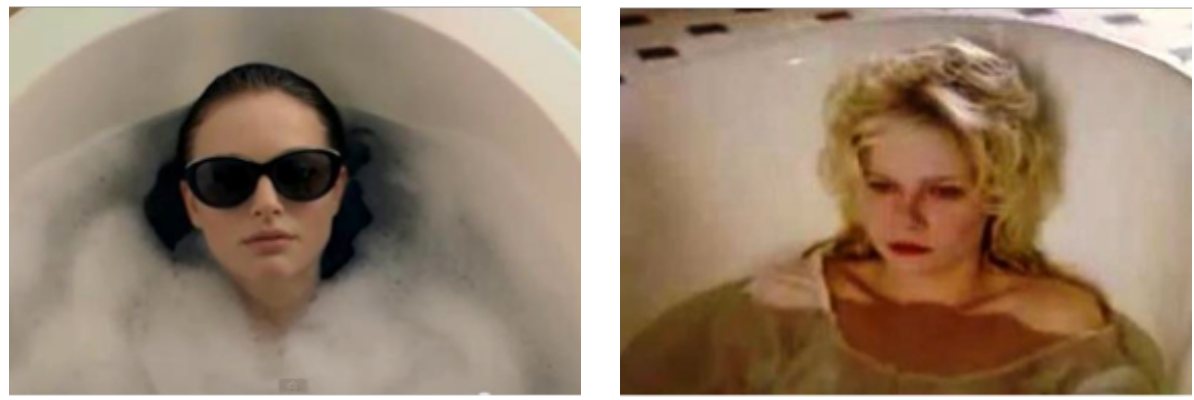

Fig.6. Frame do comercial de Sofia Coppola e frame do filme Maria Antonieta.

A peça comercial é antitética, porque Natalie representa tanto a mocinha ingênua, sonhadora e romântica como a mulher sedutora e fatal. O comercial inicia com um close do rosto da atriz diante de um ramalhete de rosas. 


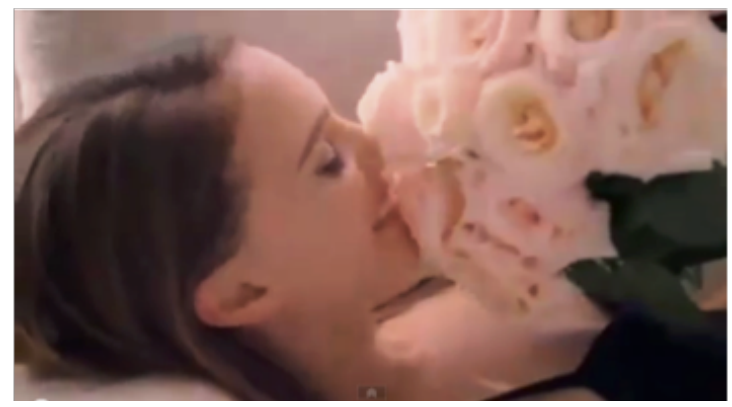

Fig.7. Frame do comercial de Sofia Coppola.

Um corte seco mostra a jovem colocando o vestido negro e fechando-o nas costas. A seguir, ela sai ao encontro do rapaz, interpretado por Alden Ehrenreich, tira a gravata dele e toma as rédeas da relação, vendando-lhe os olhos: a femme fatale entra em ação.
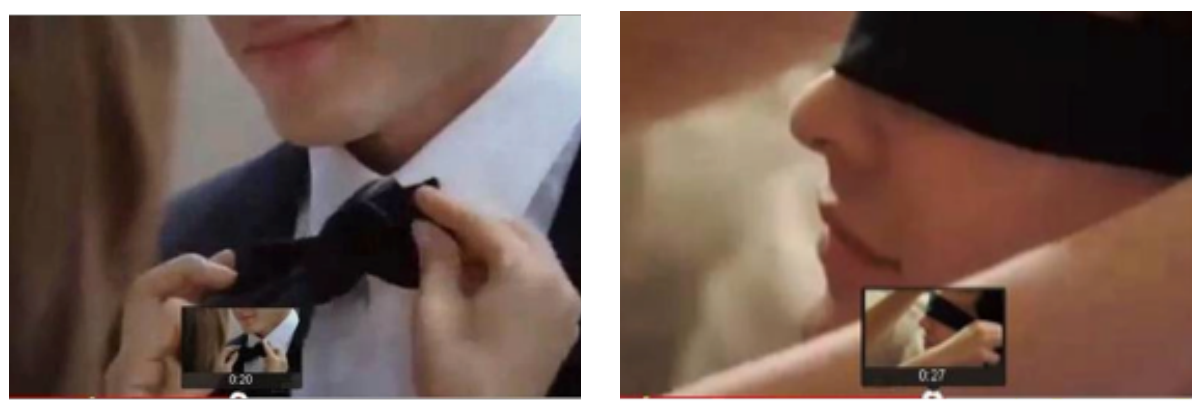

Fig.8. Frames do comercial de Sofia Coppola.

Os dois jovens protagonizam cenas que fazem referência ao ato sexual, bem ao estilo cinematográfico hollywoodiano. Ao final, volta a ambiência romântica, com um vaso das mesmas rosas do início em primeiro plano. Durante todo o comercial enfatiza-se a caracterização ambígua da personagem. Percebe-se que, nos sentimentos partilhados ou nas sensações exacerbadas provocados, o conceito de estética demonstra forma e vida; ou seja, o fluxo e o movimento dos personagens, dos ambientes e das relações ambíguas se estabelecem na peça dirigida por Coppola. Paradoxalmente, as ações sedutoras da jovem configuram-se numa espécie de romantismo retrô, numa atmosfera de contos de fadas. Observe-se como a presença das flores e a tonalidade do ambiente apelam para essa dimensão onírica, lírica e também mitopoética, ou seja, a ideia do mito como fonte imaginativa, como um fenômeno com poesia e vida própria.

Já o chamado "encantamento perverso" revela-se no comercial pelos signos gestuais, pela posição do corpo feminino e por suas ações diante do homem. O tradicional final 
feliz fica em aberto, pois a jovem está sozinha, recostada no sofá, com o vestido preto e brincando lascivamente com a gravata.

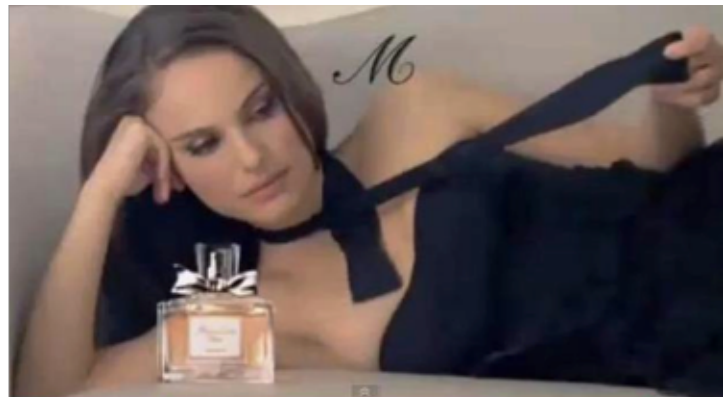

Fig.9. Frame do comercial de Sofia Coppola.

A expressão facial e as atitudes incisivas da jovem traduzem uma atmosfera erótica e sensual, ligada ao que Gilles Lipovetsky denominou "a terceira mulher". A metonímia da gravata, que a jovem retira do traje do rapaz e usa para vendar-lhe os olhos, foi uma das estratégias aplicadas para sugerir o efeito do uso do produto através da posição feminina em relação ao homem: a mulher apresentada como protagonista da sua própria vida. Revela-se, pois, uma concepção proveniente de uma nova cultura que "centrada no prazer e no sexo, no lazer e na livre escolha individual, desvalorizou um modelo de vida feminina mais voltada para a família do que para si mesma, legitimou os desejos de viver mais para si e por si" (LIPOVETSKY, 2000, p. 228-229).

\section{c) Wong Kar-Wai \& Dior Midnight Poison}

Diferentemente do primeiro caso estudado, os dois comerciais da Dior abordados, embora dirigidos por cineastas de estilos muito diferentes, são mais estereotipados e apresentam referências intertextuais a filmes atuais de sucesso. Destaquem-se alguns temas visuais recorrentes em produtos da maison Dior, como a cena do vestido escuro sendo fechado nas costas.
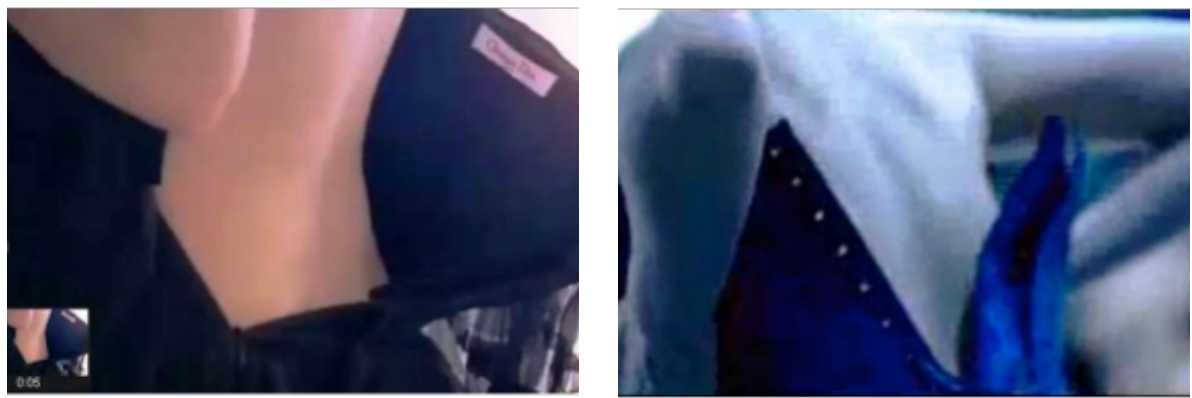

Fig. 10. Frame do comercial de Sofia Coppola e frame do comercial de Wong Kar-Wai. 
Constata-se que o comercial de Wong mantém relações temáticas com o de Coppola, muito embora, no seu todo, represente o estilo do diretor em sua fase atual. A ênfase está toda na protagonista e no artificialismo da cena; ou seja, em outro tipo de registro mimético, no qual se constata uma proposta experimental na direção de um esforço perceptivo diferenciado.

Diferentemente do que fizera em seus filmes iniciais ${ }^{6}$, nos quais conseguira criar um estilo inovador e esteticamente identificável, o diretor chinês parece aderir totalmente a Hollywood neste comercial. Ao assumir o risco da mudança, a peça aqui estudada identifica-se com o caráter polimorfo, híbrido e globalizado da cultura hodierna. Não cabe aqui expressar juízos de valor, porém sua rentável adesão ao show business, verificada também em seus filmes mais recentes, deixa nos cinéfilos um indefinível sentimento de perda que descaracterizaria a filmografia do diretor. Tratar-se-ia daquilo que Jenkins considera o impacto, tanto na produção quanto no consumo.

A convergência está ocorrendo dentro dos mesmos aparelhos, dentro das mesmas franquias, dentro das mesmas empresas, dentro do cérebro do consumidor e dentro dos mesmos grupos de fãs. A convergência envolve uma transformação tanto na forma de produzir quanto na forma de consumir os meios de comunicação (JENKINS, 2009, p. 44).

De apurada qualidade técnica e inegável apelo estético, o filme publicitário de Wong tem um roteiro bem definido e explora uma atmosfera de fantasia e exotismo, quer pela saturação de cores feita digitalmente, quer pelos ambientes compostos - com destaque para a imensa escadaria que a protagonista sobe, numa corrida frenética. Seu longo vestido azul é o exemplo do excesso neobarroco, já apontado em outro artigo nosso. Referimo-nos ao comercial do perfume Chanel $n^{\circ} 5$ dirigido por Baz Luhrmann (2004), no qual estão recontextualizados os procedimentos estilísticos barrocos. Eis as duas cenas e os vestidos.
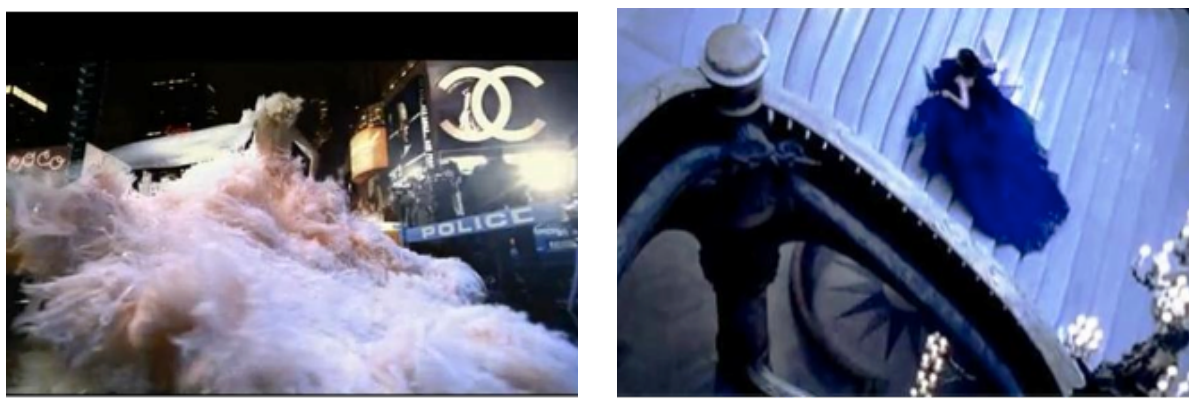

Fig.11. Frame do comercial de Baz Luhrmann e frame do comercial de Wong Kar-Wai.

Outra referência intertextual é o mesmo tom de azul saturado do comercial de Wong, além do brilho dos diamantes e dos cristais, muito explorados no filme Moulin Rouge, dirigido por Baz Luhrmann em 2001.

6 Ver nota 2. 

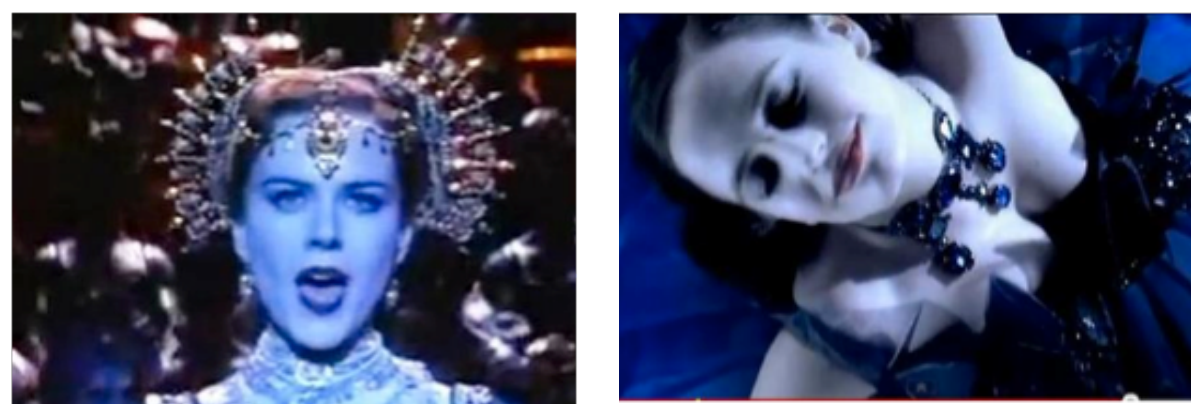

Fig.12. Frame do filme Moulin Rouge e frame do comercial de Wong Kar-Wai.

As semelhanças não param aí; porém acreditamos que a estilização de obras de outros cineastas, bem como a utilização da paródia, no sentido bakhtiniano do termo, demonstram que as escolhas feitas pelo diretor chinês explicitam a avaliação de todos os elementos, sua problematização e uma tomada de posição artística. De início, poder-se-ia pensar numa releitura da Cinderela, subindo as escadas correndo, com a ênfase reiterada no relógio que se aproxima da meia-noite. Todavia, trata-se da desconstrução do conto de fadas, porque não é a carruagem que a espera, muito menos o príncipe encantado, mas sim o público formado por fãs e sobre os quais ela se joga, pendurada em uma corda; exatamente como a Satine, interpretada por Nicole Kidman, no filme de Luhrmann. Até a expressão das duas atrizes é semelhante.

Entretanto, no comercial da fragrância Dior Midnight Poison, não aparece nem sequer um provável galã para a jovem: temos apenas ela, no auge de sua sensualidade e exuberância, num cenário luxuoso e feericamente iluminado.
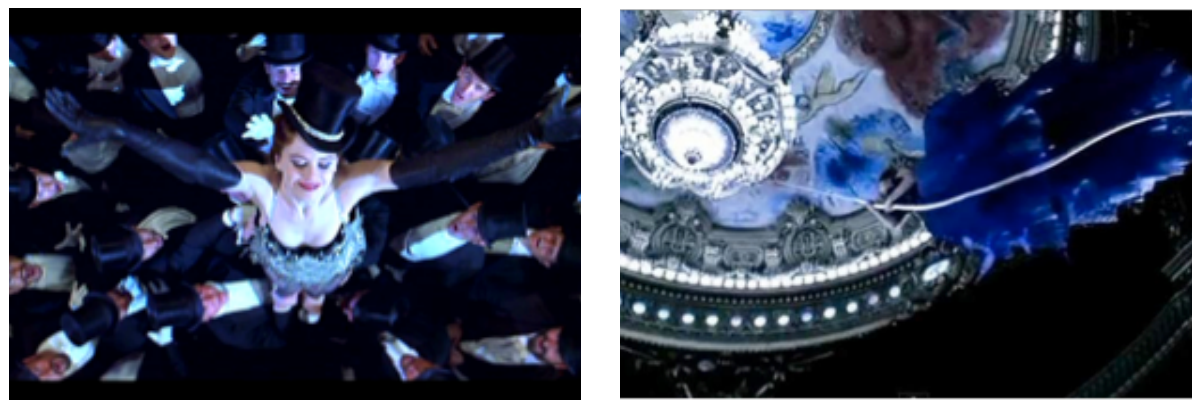

Fig.13. Frame do filme Moulin Rouge e frame do comercial de Wong Kar-Wai.

Em suma, o filme de Wong apresenta o espetáculo, acima de tudo, e a conquista da fama em lugar do final feliz romântico. Vê-se que todo o sex appeal dirige-se à plateia de admiradores e admiradoras que a aplaudem em êxtase. Nessa queda vertiginosa da 
personagem, percebe-se novamente a construção mise-en-abyme, muito utilizada em peças audiovisuais, desde produções para o cinema até videoclipes. Esse abismo transposto para o comercial da maison Dior parece seguir uma linearidade de repetições ao ponto de fuga, em outras formas, principalmente as espiraladas, como na sequência da escadaria. Nesse momento, fica sugerida uma imagem subjetiva, tomando por alguns segundos a tela, em labirintos que se suplementam em espirais de gozo e se libertam dos círculos redutores do racional. Diríamos que o filme publicitário do diretor sabe valer-se da profunda ideia da vertigem, em sua linguagem afetada, às vezes estridente, como algo que aspira à condição de enunciado artístico e precisa ser dito/apresentado de forma impressionante.

Os dois comerciais (de Coppola e de Won) nos fazem lembrar o célebre slogan do sabonete "Nove entre dez estrelas do cinema usam Lux". Podemos falar em empatia, projeção e identificação, pois o que se pretende é usar o arquétipo "atriz/modelo/pessoa famosa" como elemento de confiabilidade na construção da comunicação publicitária. Em ambos, é perceptível a construção daquilo que Morin denomina uma tendência forte da cultura de massa: o "olimpianismo", ou seja, a promoção de indivíduos a heróis, vedetes e similares. Para o autor,

[...] olimpianos são sobre-humanos no papel que eles encarnam, humanos na existência privada que eles levam. A imprensa de massa, ao mesmo tempo que investe os olimpianos de um papel mitológico, mergulha em suas vidas privadas a fim de extrair delas a substância humana que permite a identificação" (MORIN, 1977, p. 25).

O pensador considera a cultura uma ponte entre real e imaginário, fornecendo modelos de ação e conduta através de processos de identificação e de projeções que os indivíduos e grupos sociais constroem com base em símbolos culturais. Segundo Morin, no cinema, tais processos operam de forma que se tornem imaginários, uma vez que, à medida que percebemos as imagens na tela, depositamos nelas as nossas projeções-identificações, conferindo-lhes as estruturas da subjetividade, ou seja, pondo em causa as participações afetivas.

Por outro lado, a ideia de design das peças publicitárias contemporâneas integra as noções de arte, de técnica (techne) e, ainda, de mecânica e de máquina, presentes no pensamento que caracteriza o homem como artifex e ser de uma cultura cada vez mais voltada para o artificial. Essa percepção leva-nos às palavras de Vilém Flusser, quando se refere às formas das coisas, no que ele chama de um "design against nature":

This is the design that is the basis of all culture: to deceive nature by means of technology, to replace what is natural with what is artificial and build a machine out of which there comes a god who is ourselves. In short: the design behind all culture has to be deceptive enough to turn mere mammals conditionel by nature into free artists (FLUSSER, 1997, p. 19) ${ }^{7}$.

7 Tradução: Este é o design de base de toda cultura: para enganar a natureza por força da tecnologia, substituir o que é natural pelo que é artificial e construir a máquina de onde vem um deus que somos nós mesmos. Em suma: o design atrás de toda cultura tem de ser suficientemente enganoso para transformar a condição de meros mamíferos em artistas livres. 
Tendo em vista a intencional artificialidade, principalmente nos dois comerciais da Dior aqui estudados, toda a "pirotecnia" cinematográfica dos efeitos especiais coloca-se também a serviço da persuasão; eles podem ser expressivamente aproveitados, considerando a instância de recepção e a questão do repertório do público, bem como o imaginário de determinada época ou contexto.

À luz da semiótica de Charles Sanders Peirce, a interpretação de qualquer processo sígnico deve considerar os três tipos de efeitos de uma mensagem: emocionais, reativos e lógicos. Todos eles relacionam-se ao âmbito do interpretante dinâmico peirceano, ou seja, ao efeito que o signo efetivamente produz na mente do intérprete, como explicado por Lúcia Santaella:

É o interpretante singular, particular, efetivado em cada intérprete. Esse efeito pode ter três níveis: (1.3.2.1) emocional, quando o efeito se realiza como qualidade de sentimento; (1.3.2.2) energético, quando o efeito é da ordem de um esforço físico ou psicológico, uma ação física ou mental, por exemplo; (1.3.3.3) lógico, que funciona como uma regra de interpretação (SANTAELLA, 2001, p. 47).

Destarte, ao ser afetado por determinada representação de um produto, o receptor/ intérprete pode ir do puro encantamento com suas formas à curiosidade que o impele a uma reação para a busca da compreensão daquelas formas; e, finalmente, a um raciocínio lógico que o levará a conclusões/decisões sobre o que lhe é apresentado, num comercial audiovisual, por exemplo.

Ao postar em seu blog o texto "Reflexão concebida dialogicamente a partir de proposições baseadas na obra de Edgar Morin" (2011), por ele traduzido, Juremir Machado da Silva assinala que, para o pensador francês,

Mais do que a manipulação, precisamos estudar e compreender a relação da mídia com nossos imaginários. O cinema, por exemplo, corresponde ao mito de uma sociedade em ascensão, ao tempo de ascensão das classes populares, em determinada situação histórica, à condição de classes médias. Essa massa em ascensão alcança um mundo de individualismo e de vida privada, no qual o amor se torna cada vez mais importante. As estrelas embalam sonhos, difundem-se fenômenos de mimetismo, filmes retratam a busca do sucesso, de êxito na vida, mostram os percalços, servem de consolo, de estímulo, de identificação. Por momentos, modas se impõem: mimetismo na maneira de falar, nos cortes de cabelo, nas roupas, em certas atitudes (MACHADO, 2012).

É inegável que a indústria cultural, utilizando-se de diversas ferramentas disponíveis, procura suscitar no leitor ou no telespectador um sentimento de necessidade sobre determinados produtos e ideologias por ela divulgados. Não podemos efetivamente perguntar como o(a) espectador(a) se identifica com a mensagem de cada comercial sem fazer estudo de recepção; porém, cabe-nos investigar a maneira como esses públicos são 
solicitados pelas mensagens. Diante dos três comerciais aqui abordados, diríamos que eles nos permitem compreender, com Jenkins, como

\begin{abstract}
A nova "economia afetiva" incentiva as empresas a transformar as marcas naquilo que uma pessoa do meio da indústria chama de "lovemakers" e a tornar imprecisa a fronteira entre conteúdos de entretenimento e mensagens publicitárias (JENKINS, 2009, p. 48).
\end{abstract}

Em outras palavras, diríamos que a escolha e os modos de apresentação das atrizes têm inegável impacto em termos de "economia afetiva" e ajudam a moldar o "capital emocional" de cada peça audiovisual. Tais maneiras de captar a imagem feminina de forma inusitada, usadas pela arte fotográfica e pela sétima arte, acabaram também por aliar-se a outras estratégias audiovisuais nestas peças publicitárias veiculadas, saliente-se, nos canais pagos da TV, o que, imagina-se, sinaliza a um consumo e a uma audiência predefinidas.

\title{
Ponderações finais
}

Poderíamos inferir que os recentes comerciais televisivos de perfumes femininos visam induzir os modos de presença da mulher atual, numa cena sociocultural centrada em atributos físicos performáticos ligados ao status, ao sexy appeal e ao prazer. Dionisíaco e apolíneo entrelaçam-se nos contornos corporais perfeitos das personagens dos comerciais das diferentes fragrâncias de grifes, eleitas pelas próprias mídias como desejáveis, conferindo-Ihes tonalidades míticas e uma espécie de ascese laica.

Em artigo publicado na revista Screen "Visual Pleasure and Narrative Cinema", em 1975, Laura Mulvey busca na teoria psicanalítica os fundamentos para uma profunda crítica da imagem cinematográfica, principalmente a de Hollywood, como um produto da predominância do olhar masculino, relegando a mulher a um objeto passivo. A autora utiliza-se de uma espécie de "arma política" para desmascarar as maneiras como "o inconsciente da sociedade patriarcal ajuda a estruturar a forma do cinema". (MULVEY, 1975, p.14) ${ }^{8}$. Escopofilia, voyeurismo, complexo de castração, narcisismo e, sobretudo, fetichismo são conceitos freudianos que o artigo estabelece como o mecanismo de prazer e plenitude do cinema narrativo de ficção. A autora propõe a destruição dessa forma de prazer e a produção de uma "nova linguagem do desejo" (ibidem).

Mais recentemente, no artigo "Film and the Masquerade: Theorizing the Female Spectator" (1992), Mary Ann Doane desloca a oposição de Mulvey sobre ativo/passivo para a dicotomia distância/proximidade ao propor outros modelos para interpretar as diferenças no olhar. Segundo a autora, a espectadora feminina seria a própria imagem, ou seja, uma sobrepresença da imagem. Haveria, na contemporaneidade, uma ostentação excessiva de feminilidade, que pode ser agora assumida e usada como uma máscara e a apresentação da personagem feminina como portadora e controladora do olhar; como

8 No Brasil, o artigo foi publicado na coletânea A experiência do cinema, organizada por Ismail Xavier (1983). 
parece ocorrer nos comerciais aqui abordados. Destarte, como em outras propagandas similares, as imagens criadas de atrizes ou modelos gerariam o que Alison Lurie (1997) chama de status por associação, ou seja, a apropriação de uma magia ou de uma aura simpática na busca pela imitação das características de "perfeição" nelas encontradas.

Denise Azevedo Duarte Guimarães é professora e pesquisadora no Programa do Mestrado e Doutorado em Comunicação e Linguagens da Universidade Tuiuti do Paraná e professora dos Cursos de Graduação em Comunicação e em Letras. É doutora em Estudos Literários pela Universidade Federal do Paraná. É docente-fundadora e vice-coordenadora da Pós-Graduação em Cinema da UTP denise.guimaraes@utp.br

\section{Referências}

ADORNO, Theodor et al. Teoria da cultura de massa. São Paulo: Paz e Terra, 2000.

BAKHTIN, Mikhail. The dialogic imagination. Austin: University of Texas Press, 1982.

BAUDRILLARD, Jean. Simulacres et simulation. Paris: Ed. Gallilée, 1993.

BAUMAN, Zygmunt. Vida para consumo. A transformação das pessoas em mercadoria. Rio de Janeiro: Jorge Zahar, 2008.

CANCLINI, Néstor García. Culturas híbridas. Estratégias para entrar e sair da modernidade. São Paulo: Edusp, 2008.

COVALESKI, Rogério. Cinema, publicidade, interfaces. Curitiba: Maxi Editora, 2009.

DOANE, Mary Ann. Film and the Masquerade: Theorizing the Female Spectator. In: Screen. Sexual Subjects: a Screen Reader in Sexuality. London: Routledge, 1992. p. 227-243.

ETCOFF, Nancy. A lei do mais belo - a ciência da beleza. Rio de Janeiro: Objetiva, 1999.

FLUSSER, Vilém. The shape of Things. Philosophy of Design. London: Reaktion Books, 1997.

JENKINS, Henry. Cultura da convergência. 2 ed. São Paulo: Aleph, 2009.

JUNG, Carl Gustav. Os arquétipos e o inconsciente coletivo. Petrópolis: Vozes, 2000.

LIPOVETSKY, Gilles. A terceira mulher. São Paulo: Companhia das Letras, 2000. LURIE, Alison. A linguagem das roupas. Rio de Janeiro: Rocco, 1997.

MACHADO, Juremir. A comunicação segundo Edgar Morin. Disponível em: <http://www.correiodopovo.com.br/blogs/juremirmachado/?p=1134.2011> Acesso em: 15 maio 2012.

MANOVICH, Lev. The Language of New Media. Cambridge: The MIT Press, 2001.

MORIN, Edgar. Le Cinéma ou l'Homme Imaginaire. Paris: Minuit, 1956.

As estrelas: mito e sedução no cinema. Rio de Janeiro: José Olympio, 1989. 
. A minha esquerda. Porto Alegre: Sulina, 2011.

MULVEY, Laura. Visual Pleasure and Narrative Cinema. In: Screen, vol. 16, n. 3. London: Routledge, 1975. p. 6-27.

PEIRCE, Charles Sanders. Semiótica. São Paulo: Perspectiva, 1990.

ROCHA, Everardo (Org.). Representações do consumo: estudos sobre a narrativa publicitária. Rio de Janeiro: Ed. PUC-Rio, Mauad, 2006.

SANTAELLA, Lúcia. Matrizes da linguagem e pensamento. São Paulo: Iluminuras, 2001.

SANTANA, Armando. Propaganda - teoria, técnica e prática. São Paulo: Pioneira, 1996.

STEELE, Valerie. Fetiche: moda, sexo e poder. Rio de Janeiro: Rocco, 1997.

THOMPSON, John B. A mídia e a modernidade: uma teoria social da mídia. Petrópolis: Vozes, 1998.

VANDERSCHELDEN, Isabelle. Amélie: Le Fabuleux Destin D'Amélie Poulain. London: Tauris \& Co. Ltd., 2007.

VÍDEOS DOS COMERCIAIS. Disponível em: <www.youtube.com/watch?>. Acessos em: 12 jan. 2011; 11 fev. 2012; 15 maio 2012.

Artigo recebido em julho

e aprovado em setembro de 2012. 